\title{
Occurrence of venlafaxine residues and its metabolites in marine mussels at trace levels: development of analytical method and a monitoring program
}

\author{
M. J. Martínez Bueno • C. Boillot • D. Munaron • \\ H. Fenet • C. Casellas • E. Gómez
}

Received: 23 July 2013 /Revised: 25 October 2013 / Accepted: 31 October 2013 / Published online: 4 December 2013

(C) Springer-Verlag Berlin Heidelberg 2013

\begin{abstract}
Coastal areas are subject to growing pressures and impacts because of the increase in human activities. Lipophilic organic contaminants, such as polycyclic aromatic hydrocarbons (PAHs) or polychlorinated biphenyls (PCBs), have been monitored for decades within monitoring programs. However, until now, little information on the detection of so-called "emerging contaminants" such as hydrophilic organic compounds in the marine environment and no data on its metabolites or transformation products in marine organisms is available. In this report, a sensitive analytical methodology for identification and confirmation of venlafaxine (VEN) residues and five of its main metabolites in the marine mussels Mytilus galloprovincialis was validated. The sample preparation procedure was based on the Quick, Easy, Cheap, Effective, Rugged, and Safe (QuEChERS) approach. An analytical method was developed to quantify these compounds at trace levels by liquid chromatography coupled to high-resolution mass spectrometry. The method was then applied to marine mussels collected from the Mediterranean Sea in southeastern France. Residues of the antidepressant VEN were occasionally detected at $\mathrm{ng} / \mathrm{g} \mathrm{dw}$ level. In addition, the approach allowed us to identify several transformation products in the analyzed samples. $N$-desmethylvenlafaxine (NDV) was the most frequently detected metabolite followed by $N$, O-didesmethylvenlafaxine (NODDV).
\end{abstract}

\footnotetext{
M. J. Martínez Bueno $(\bowtie) \cdot$ C. Boillot $\cdot$ H. Fenet $\cdot$ C. Casellas

E. Gómez

Hydrosciences Montpellier UMR 5569, Department of Environmental Sciences and Public Health, University of Montpellier, I, 34000 Montpellier, France

e-mail: mjbueno@ual.es

D. Munaron

IFREMER, Environment Resources Laboratories of the Languedoc-Roussillon, 34203 Sete, France
}

Keywords Antidepressant · Emerging contaminants . Transformation products · Marine organisms · Orbitrap · QuEChERS

\section{Introduction}

Public interest regarding the presence of pharmaceuticals in the environment is mounting [1]. In Europe, around 3000 different pharmaceutical active compounds used as human and veterinary drugs may reach every environmental compartment. Coastal areas are subject to growing pressures and impacts due to increasing human activities. In view of serious threats to the European coasts, the European Parliament and the Council approved Recommendation 2002/413/CE concerning the implementation of Integrated Coastal Zone Management in Europe in order to improve the water quality [2].

Venlafaxine (VEN) is an antidepressant drug prescribed for the treatment of clinical depression and anxiety disorders. It is one of the most commonly prescribed classes of pharmaceuticals in the world. Approximately $29 \%$ of a VEN applied dose is excreted in the urine within 48 hours as the unconjugated metabolite O-desmethylvenlafaxine (ODV), whereas only $5 \%$ of the amount is excreted as unchanged parent compound [3]. Some publications have reported that maternal exposure to this antidepressant elevates fetal plasma serotonin levels, which has been associated with autism and increased risk of spontaneous abortion [4]. Regarding its aquatic fate, recent studies have indicated the presence of VEN in wastewater effluent [5-7], surface water [8-10], and even drinking water [11]. About the detection of its transformation products in the environment, Lajeunesse et al. [6] reported, for the first time, the occurrence of ODV in Canadian municipal wastewater at levels ranging from 21 to $68 \mathrm{ng} / \mathrm{L}$. More recently, it has been identified in effluents from waste water treatment plants (WWTPs) and surface waters in Germany, at 
concentrations up to 500 and $743 \mathrm{ng} / \mathrm{L}$, respectively [7, 12]. The removal rates published for both compounds in the conventional wastewater treatment plants are about $40 \%$ [9]. However, to our knowledge, no data exist regarding presence of such substances in coastal marine waters. This issue can be partly explained by sampling complexity and the lack of suitable analytical methodologies in those environmental compartments where higher sensitivity is required because of higher dilution rates [13]. Traditional sampling techniques using discrete water sampling are not well suited to such purpose. On the other hand, the present generation of passive samplers enables detection of micro-organic contaminants at low concentrations. Nevertheless, some authors have suggested that passive samplers must still be further developed and validated, in situ, since laboratory conditions generally differ too greatly from those in the field $[14,15]$.

To overcome this difference, the use of marine organisms as a tool for the monitoring of a pharmaceutical and its transformation products in marine environments was evaluated in the present study. Mediterranean mussel ( $M$. galloprovincialis) is a common filter feeder widely distributed in sea coasts. According to the claims of some authors, this species is an excellent sentinel for monitoring of organic micro-pollutants because it can bioaccumulate substances through their gills (dissolved substances) and/or digestive tract (substances adsorbed on particles) [16, 17], in function of the solubility properties and the octanol/water partition coefficient $\left(\mathrm{K}_{\mathrm{ow}}\right)$ of each compounds, between other properties. Then again, an estimated bioconcentration factor (BCF) of 60 suggests a moderate potential for bioconcentration in aquatic organisms for the case of VEN [18]. But up to now, the few studies of the presence of antidepressants in aquatic organisms outside the laboratory have focused on fluoxetine, sertraline, serotonine, or norfluoxetine. Such research showed that these substances were present in fish sampled from effluentimpacted rivers $[8,19,20]$. Little information on the detection of VEN and its metabolites in aquatic organisms and no data in marine organisms are available in literature.

So, the objectives of this study were as flows: (1) to develop and validate a simple, rapid, and sensitive analytical approach for detection, characterization, and quantification of venlafaxine residues and five of its main metabolites in marine mussels. For that, an easy QuEChERS [21] extraction method combined with liquid chromatography mass spectrometry system was the procedure validated and described in this study. Accurate mass measurements in MS and MS/MS modes were performed in the same run, which are highly useful for the identification of isomeric compounds, a common problem when several transformation products are analyzed. The more demanding requirements regarding mass spectrometric confirmation currently set by EU regulations (Commission Decision 2002/657/EC and SANCO/10684/ 2009 Guideline) were taken into account $[22,23]$. Therefore, a total of five identification points were obtained for each analyte, limiting the number of false positive results in order to achieve suitable identifications; (2) to evaluate the use of marine organisms as a tool for monitoring of venlafaxine residues and its metabolites in aquatic environments; and (3) to demonstrate the utility of the method by providing new results on the contamination of French coastal areas by emerging contaminants, as well as by their transformation products.

\section{Experimental}

\section{Chemicals and reagents}

The structure and physiochemical properties of target analytes are listed in Table 1. $N, N$-didesmethyl-O desmethylvenlafaxine (NNDDODV), $N, O$-didesmethylvenlafaxine (NODDV), $O$ desmethylvenlafaxine (ODV), $N$-desmethylvenlafaxine (NDV), N,N-didesmethylvenlafaxine (NNDDV)n and venlafaxine-d6 (VEN-d6) were purchased at analytical grade (purity $>90 \%$ ) from Toronto Research Chemicals Inc. (Toronto, ON, Canada), except venlafaxine (VEN), which was obtained from Sigma-Aldrich (Steinheim, Germany). Stock standard solutions of individual compounds were prepared at a concentration of $1 \mathrm{mg} / \mathrm{ml}$ in methanol. All the standard solutions were stored at $-20^{\circ} \mathrm{C}$.

Ultrapure water, methanol (MeOH), and HPLC-grade acetonitrile (AcN) were supplied by Carlo Erba (Val de Reuil, France). Formic acid (purity, $98 \%$ ) was obtained from Fisher Labosi (Elancourt, France). QuEChERS material: sodium sulfate $\left(\mathrm{Na}_{2} \mathrm{SO}_{4}\right)$ anhydrous and sodium chloride $(\mathrm{NaCl})$ were obtained from Carlo Erba. Sodium citrate dihydrate $\left(\mathrm{Na}_{3} \mathrm{Cit}: 2 \mathrm{H}_{2} \mathrm{O}\right)$ and sodium citrate dibasic sesquihydrate $\left(\mathrm{Na}_{2} \mathrm{HCit}: 3 \mathrm{H}_{2} \mathrm{O}\right)$ were purchased from Sigma-Aldrich (St. Louis, MO, USA). Dispersive SPE tubes containing Z-SepPlus $(500 \mathrm{mg} / 12 \mathrm{~mL}$ ) and primary secondary amine (PSA) sorbent were obtained from Supelco (Bellefonte, PA, USA) and C-18 (40 $\mu \mathrm{m}$ particle size) from Varian (Palo alto, CA, USA), respectively. The calibration mixture for the mass spectrometer MSCAL5-1EA (caffeine, tetrapeptide "MetArg-Phe-Ala", ultramark) was purchased from Supelco.

Samples and sample preparation

Marine mussels were collected from different zones of the Mediterranean Sea located in southeaster France (Montpellier and Marseille). Since the monitoring campaign carried out in Montpellier, 23 samples were collected from different sites: (1) directly from the outlets before exposure (To); (2) from production cultures (Ref); (3) from an important lagoon with substantial harbour activity and very influenced by human settlements (IM); and (4) in the vicinity of a submarine outfall 
Table 1 Physicochemical properties of venlafaxine and its metabolites

\begin{tabular}{|c|c|c|c|c|c|c|}
\hline Analyte & $\begin{array}{c}\text { Molecular } \\
\text { structure }\end{array}$ & $\begin{array}{c}\text { Molecular } \\
\text { formula }\end{array}$ & $\begin{array}{l}\text { CAS } \\
\mathbf{N}^{\circ} \text {. }\end{array}$ & $\begin{array}{c}\text { Molecular } \\
\text { weight }\end{array}$ & $\begin{array}{c}\text { Water } \\
\text { solubility a }\end{array}$ & $\begin{array}{r}\log \\
K_{0 \mathrm{w}} \\
\end{array}$ \\
\hline NNDDODV & & $\mathrm{C}_{14} \mathrm{H}_{21} \mathrm{NO}_{2}$ & $135308-76-8$ & 235.1566 & - & - \\
\hline NODDV & & $\mathrm{C}_{15} \mathrm{H}_{22} \mathrm{NO}_{2}$ & $135308-74-6$ & 249.1723 & - & - \\
\hline ODV & & $\mathrm{C}_{16} \mathrm{H}_{25} \mathrm{NO}_{2}$ & $93413-62-8$ & 263.1879 & 3670 & 2.72 \\
\hline NNDDV & & $\mathrm{C}_{15} \mathrm{H}_{23} \mathrm{NO}_{2}$ & 93413-77-5 & 249.1723 & - & - \\
\hline NDV & & $\mathrm{C}_{16} \mathrm{H}_{25} \mathrm{NO}_{2}$ & $149289-30-5$ & 263.1879 & 485.2 & 3.07 \\
\hline VEN & & $\mathrm{C}_{17} \mathrm{H}_{27} \mathrm{NO}_{2}$ & $99300-78-4$ & 277.2036 & 266.7 & 3.28 \\
\hline
\end{tabular}

a, b Predicted data cited from chemspider.com, which is generated using US Environmental Protection Agency's EPI Suite ${ }^{\mathrm{TM}}$ (KOWWIN v1.67 estimate). Data of water solubility at $25^{\circ} \mathrm{C}(\mathrm{mg} / \mathrm{L})$.

with industrial/urban discharges (N,E,O). In order to monitor the fluctuations in the occurrence of target compounds due to site variation, one additional campaign was performed from samples collected in Marseille $(n=7)$ in the vicinity of a marine outfall $(\mathrm{N}, \mathrm{E})$. Moreover, four mussel samples were randomly purchased in different local markets in the Montpellier area. So, a total of 34 samples were analyzed in different monitoring campaigns performed from 2011 to 2013. In order to reduce the variability effect due to use of organic matrix, each composite sample consisted of 50 mussels of similar size (4-5 cm length) collected from each sampling site. Mussels were cleaned of sedimentary material, epiphytes, and epifauna, washed, and then the flesh was separated from the shell. Samples were then stored at $-20^{\circ} \mathrm{C}$ until their treatment. Mussels were freeze-dried (Heto Power dry LL 3000, Thermo), homogenized and grounded into powder using MM-2 vibrational mill (Retsch, Haan, Germany). Each sample was then placed inside a clean and opaque glass bottle and stored in dark until extraction and analysis.

\section{Sample extraction}

Sample preparation was based on extraction with water and $\mathrm{AcN}$ with subsequent salt-induced phase partitioning. The procedure used is a modification of a previously reported method for the determination of carbamazepine in marine mussel, developed by our team [24]. Briefly, sample treatment by QuEChER approach was based on $2 \mathrm{~g} \pm 0.01$ freeze-dried mussels were weighed in a $50 \mathrm{~mL}$ polypropylene centrifuge tube and spiked with surrogate standard (VEN-d6). Next, the mussels were rehydrated by adding $10 \mathrm{~mL}$ of ultrapure water.
The tubes were then vigorously shaken manually for $2 \mathrm{~min}$, after the addition $10 \mathrm{~mL}$ of AcN. Then QuEChERS salts $(4 \mathrm{~g}$ $\mathrm{Na}_{2} \mathrm{SO}_{4}$ (anh), $1 \mathrm{~g} \mathrm{NaCl}, 1 \mathrm{~g} \mathrm{Na}_{3} \mathrm{Cit}: 2 \mathrm{H}_{2} \mathrm{O}$, and $0.5 \mathrm{~g}$ $\mathrm{Na}_{2} \mathrm{HCit}: 3 \mathrm{H}_{2} \mathrm{O}$ ) were added and the mixture was immediately vigorously shaken (manually) for $1 \mathrm{~min}$ more. After the centrifugation step ( $3500 \mathrm{rpm}, 5 \mathrm{~min}$ ), $2.5 \mathrm{~mL}$ of the upper AcN layer was transferred into a Z-Sep-plus tube and $50 \mu \mathrm{L}$ of formic acid was added and shaken for $1 \mathrm{~min}$. Z-Sep material contain zirconium atoms, which act as a Lewis acid [24]. Then, $1 \mathrm{~mL}$ of mixture was evaporated to dryness. The residue was reconstituted in $1 \mathrm{~mL}$ of AcN/water (1:9, vol/vol). Finally, the sample was centrifuged at $10,000 \mathrm{rpm}$ for $10 \mathrm{~min}$ to separate the residual lipids, and the extract was filtered directly into an analysis vial using a $0.45 \mu \mathrm{m}$ PTEF syringe filter.

\section{LC-MS analysis}

The separation of the analytes was carried out using an HPLC (Accela 1250 Pump and a degasser, Thermo Scientific, San Jose, CA, USA) equipped with a C18 analytical column, $100 \mathrm{~mm}$ length $\times 2.1 \mathrm{~mm}$ i.d. and $1.8 \mu \mathrm{m}$ particle size (ZORBAX XDB, Agilent Technologies, Wilmington, DE, USA). The LC mobile phases were AcN (A) and water (B) both containing $0.1 \%$ formic acid. The optimal separation was achieved using a $200 \mu \mathrm{L} / \mathrm{min}$ flow rate and the following gradient: $1 \mathrm{~min}$ isocratic at $10 \% \mathrm{~A}$, then a linear gradient to $100 \% \mathrm{~A}$ at $8 \mathrm{~min}$, and finally $5 \mathrm{~min}$ isocratic at $100 \% \mathrm{~A}$. After that, $7 \mathrm{~min}$ of post-time followed using the initial $10 \%$ of A. The volume of injection was $10 \mu \mathrm{L}$. For analysis, an Exactive LCMS (Thermo Fisher Scientific) system equipped with a heated electrospray ionization probe (HESI) source in positive ion 
mode was used. The HESI parameters were: electrospray voltage, $4.0 \mathrm{kV}$; sheath gas, 35 arbitrary units; auxiliary gas, 10 arbitrary units. The heater in the source was set to $200^{\circ} \mathrm{C}$ and the heated capillary in the mass spectrometer was operated at $300{ }^{\circ} \mathrm{C}$. Data were acquired by continuously alternating full MS and MS/MS modes: one without and one with fragmentation (both $m / z$ 150-350). For fragmentation, an additional experiment using a higher-energy collisional dissociation (HCD) cell fixed at $15 \mathrm{eV}$, was included in the run. The resolving power for both scan events was 50,000 FWHM at $0.25 \mathrm{~s}$ for each one. The automatic gain control (AGC) target was set to $1 \times 10^{6}$ ions (balance scan). All the other parameters for the mass spectrometer (tube lens, skimmer, and capillary voltage) were automatically tuned to obtain the highest TIC signal. The final values were 70,16 , and $65 \mathrm{~V}$, respectively. Confirmation of each compound was performed by means of (1) retention times, (2) mass accuracy $<5 \mathrm{ppm}$ in full scan MS of protonated molecule $[\mathrm{M}+\mathrm{H}]$, and (3) the acquisition of at least one fragment ion together a mass accuracy $<5 \mathrm{ppm}$ in full scan MS/MS. The second diagnostic ion should be sensitive and selective, with a variation of the abundance relative within a certain range [23]. Figure 1 show the extracted ion chromatogram (XIC) and product ion mass spectrum obtained in MS and MS/MS mode, of the protonated target compounds using fragmentation energy of $15 \mathrm{eV}$ for a mussel sample spiked at $1 \mathrm{ng} / \mathrm{g}$.

\section{Method validation}

A rigorous validation procedure according to $\mathrm{SANCO} / 10684 /$ 2009 and ISO/17025 Guidelines was performed to ensure high quality analytical measurements [23, 25]. Method accuracy and precision were evaluated by recovery studies using blank mussel samples spiked at two concentration levels 5 and $50 \mathrm{ng} / \mathrm{g} \mathrm{dw}$. All experiments were tested with six replicates, in accordance with the recommendations of EU guidelines cited above. Quantitation of the compounds in the spiked samples was carried out by comparing the peak areas of the samples with those of matrix matched standard solutions. These, as well as the matrix-matched calibration curves, were prepared by spiking an aliquot of the blank extract with the desired amount of standard solution. The sensitivity of the method was calculated in terms of limit of quantitation (LOQ) and limits of detection (LOD), which were calculated as the minimum concentration of analyte that generated a signal to noise $(\mathrm{S} / \mathrm{N})$ ratio of 10 and 3, respectively, from signal obtained on matrix-matched calibration curves. Linearity was evaluated both in solvent and matrix, using matrix-matched calibration curves prepared as described before, in a concentration range of $0.1-10 \mathrm{ng} / \mathrm{g}$. The matrix effect was studied by comparison of the slopes of the calibration curves in solvent and in matrix. The repeatability of the instrumental method was estimated by determining the inter- and intra-day (relative SD, \%) by the repeated analysis $(\mathrm{n}=5)$ of a spiked matrix extract at $1 \mathrm{ng} / \mathrm{g}$, from run-to-run over one day and five days, respectively.

Finally, in order to ensure quality measurements, each day before analysis the calibration of Exactive mass spectrometer was performed using the calibration mixture. After that, a standard mixture $(10 \mathrm{ng} / \mathrm{L})$ containing targeted analytes was injected with the purpose of checking the performance of the HPLC, analytical column, and Orbitrap MS system. A continuous monitoring of the quality of the analytical procedure was carried out through the inclusion of blank (solvent) during the day-work sequence.

\section{Results and discussion}

Method validation results

The more demanding requirements regarding mass spectrometric confirmation currently set by EU regulations were taken into account for confirmation and quantification of each target compound. Commission Decision 2002/657/EC [22] describes a system of identification to obtain a minimum of four identification points, in which, detection of transition products in $\mathrm{HR}-\mathrm{MS}^{\mathrm{n}}$ yields two identification points per ion. SANCO/10684/2009 Guideline [23] recommended the acquisition of $\geq 2$ diagnostic ions (preferably including the quasimolecular ion and at least one fragment ion) and a mass accuracy $<5 \mathrm{ppm}$. In this way, the adquisition of one exact precursor ion and one exact product ion, along with the retention time, allowed us to obtain a total of five identification points per compound as identification criteria in this study. Therefore, the issue of false positive results for analytical methods at ultra-trace levels in which analyte detection is based on retention time and only one exact mass was resolved.

\section{Recoveries}

The accuracy of the method was verified by measuring recoveries from blank mussel spiked with 5 and $50 \mathrm{ng} / \mathrm{g}$ dw of each chemical. These levels would imply 1 and $10 \mathrm{ng} / \mathrm{g}$, in the final extract. All experiments were performed by 6 -fold for each matrix. The mean recovery data and deviations obtained, which highlights the precision of the extraction method, are given in Table 2. Mussels are fat- or lipid-containing matrices (about $15 \%$ ) and, although fats are not very soluble in $\mathrm{AcN}$, a certain quantity of them will be co-extracted, so they have to be removed prior to the final determination step [24]. For that, a new sorbent material Z-Sep-plus used to enhance matrix interference removal was evaluated in this study. They contain zirconium atoms, which act as a Lewis acid, while the phosphate groups in phospholipids act as a strong Lewis base, strongly binding with zirconium atoms. According to the manufacture's specifications, these sorbents can significantly 


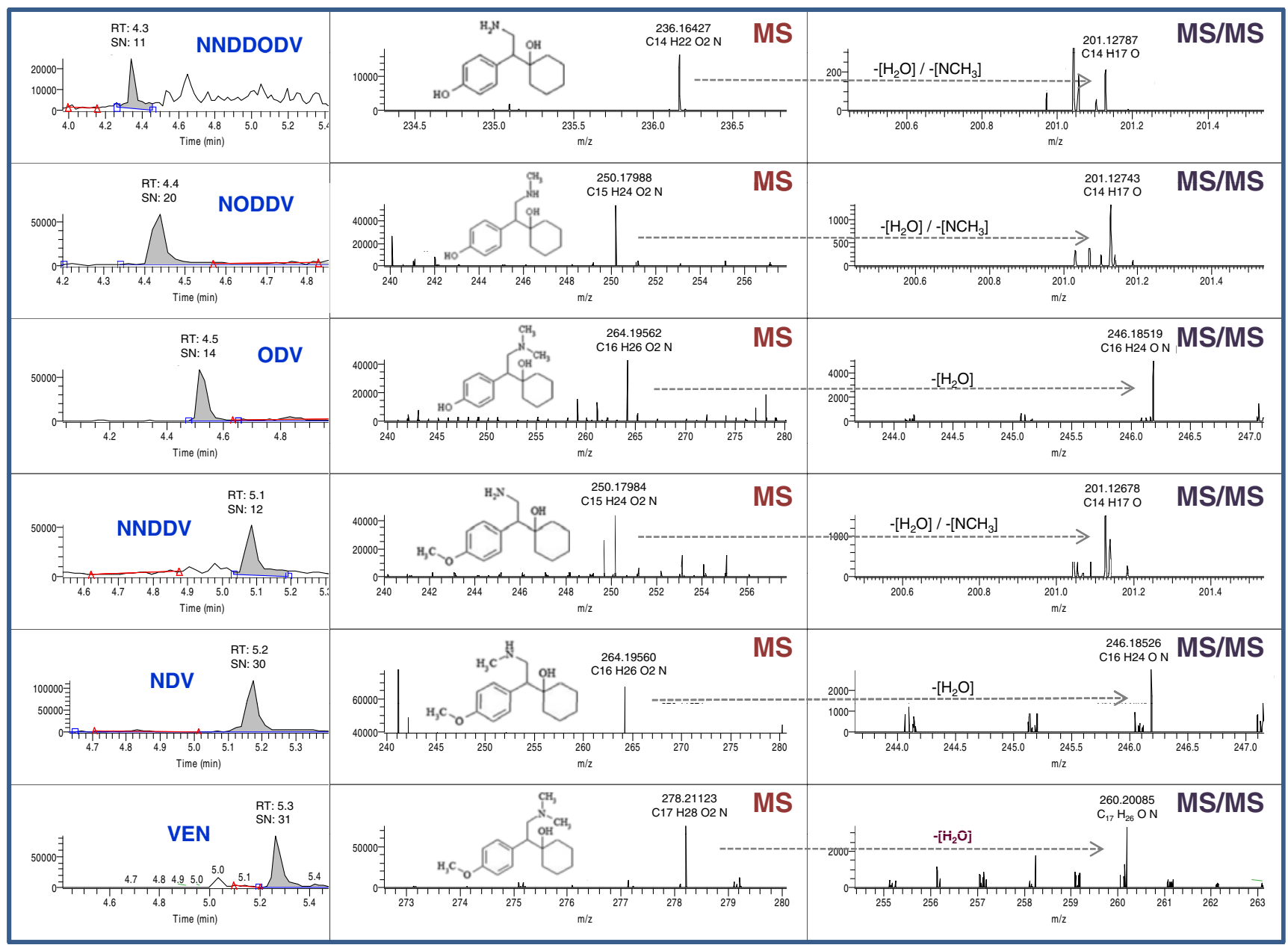

Fig. 1 Chromatogram, precursor, and product ion mass spectrum obtained in MS and MS/MS mode for each target analyte using a fragmentation energy of $15 \mathrm{eV}$ at $1 \mathrm{ng} / \mathrm{g}$ in a mussel extract

remove fatty matrix interferences and color from sample extracts, providing more robust LC/MS methods. Satisfactory recoveries for all selected compounds were achieved by developed QuEChERS approach. The average recovery values for both spike levels were higher than $70 \%$, except for metabolite NNDDV (61 \%) and NNDDODV (55\%) at

Table 2 Analytical performance data for each target compound studied by LC-Orbitrap-MS method

\begin{tabular}{|c|c|c|c|c|c|c|c|}
\hline Compound & Matrix Effect & Inter/intra-day (R.S.D, \%) & Rec. $\%( \pm \sigma)$ & LOQ (ng/g) & LOD (ng/g) & MQL (ng/g) & MDL (ng/g) \\
\hline NNDDODV & 16 & $6 / 8$ & $\begin{array}{l}55(9)^{\mathrm{a}} \\
70(8)^{\mathrm{b}}\end{array}$ & 0.7 & 0.2 & 3.6 & 1.1 \\
\hline NODDV & -31 & $5 / 14$ & $\begin{array}{l}78(5)^{\mathrm{a}} \\
70(3)^{\mathrm{b}}\end{array}$ & 0.6 & 0.2 & 3.0 & 1.0 \\
\hline ODV & -30 & $4 / 13$ & $\begin{array}{l}78(5)^{\mathrm{a}} \\
79(3)^{\mathrm{b}}\end{array}$ & 0.7 & 0.2 & 3.5 & 1.1 \\
\hline NNDDV & 19 & $4 / 3$ & $\begin{array}{l}61(6)^{\mathrm{a}} \\
61(2)^{\mathrm{b}}\end{array}$ & 0.8 & 0.3 & 3.8 & 1.5 \\
\hline NDV & 4 & $2 / 5$ & $\begin{array}{l}76(3)^{\mathrm{a}} \\
71(2)^{\mathrm{b}}\end{array}$ & 0.5 & 0.1 & 2.5 & 0.5 \\
\hline VEN & 8 & $1 / 3$ & $\begin{array}{l}88(3)^{\mathrm{a}} \\
80(4)^{\mathrm{b}}\end{array}$ & 0.5 & 0.1 & 2.5 & 0.5 \\
\hline
\end{tabular}

Inter/intra-day: repeatability/reproducibility of the instrumental method (R.S.D, \%); R.S.D: relative standard deviation; Rec: recovery average values obtained at two spiked levels (a) and (b), 5 and $50 \mathrm{ng} / \mathrm{g}$, respectively; $\sigma$ : dispersion from the average recovery values; LOQ: limit of quantification; LOD: limit of detection; MQL: method quantification limit; MDL: method detection limit. 
$5 \mathrm{ng} / \mathrm{g}$ level. Finally, highlight the importance of the addition of formic acid. Many sample preparation techniques for biological matrices use acid to disrupt compound-protein binding, which directly affects recovery and matrix effect [24]. Thus, the addition of $2 \%$ formic acid was a critical step. In the absence of this additive, recoveries were reduced to more than half $(<30 \%$, data not included).

\section{Linearity and matrix effect}

The linearity of the analytical response was evaluated using solvent and matrix-matched calibration curves at five concentration levels covering three orders of magnitude: from 0.1 to $10 \mathrm{ng} / \mathrm{g}$, based on linear regression and squared correlation coefficient $\left(r^{2}\right)$. All the studied compounds presented a very good response of three orders of magnitude, with correlation coefficients higher than 0.997 in all cases.

Matrix effect was also evaluated during the validation of the method. In fact, signal suppression or enhancement can severely compromise quantitative analysis of the compounds at trace levels, as well as affect the method reproducibility and accuracy [26]. The matrix effect was studied by comparison of the slopes of the calibration curves in solvent and in matrix. When the percentage of the difference between these slopes is positive, there is signal enhancement, whereas a negative value indicates signal suppression. According to our results (Table 2), five compounds showed no matrix effect $(<20 \%$, because this variation is close to the repeatability values), and only two metabolites, NODDV and ODV, presented a medium effect $(<31 \%)$. In spite of these low values, matrix-matched calibration curves were used to compensate the matrix effect and avoid any under/over estimation during the quantification.

\section{Precision}

In order to evaluate the repeatability of the instrumental method, the intra- and inter-day relative SD were studied. Method repeatability was determined at $10 \mathrm{ng} / \mathrm{g}$, by the analysis of five spiked matrix extracts. Relative SD values for intra-day (repeatability) ranged between $1 \%$ and $6 \%$. The reproducibility (inter-day) was calculated during five consecutive days, and it varied from $3 \%$ to $14 \%$ (see Table 2). This demonstrates the repeatability of the method and therefore its effectiveness for quantitative purposes.

\section{Sensitivity}

The sensitivity of the method was calculated in terms of limit of quantitation (LOQ) and limit of detection (LOD), which were estimated as the minimum concentration of analyte that generated a $\mathrm{S} / \mathrm{N}$ of 10 and 3, respectively, from signal obtained to matrix-matched calibration curves. The reporting levels of the studied compounds range from 0.1 to $0.3 \mathrm{ng} / \mathrm{g}$ (LOD) and 0.5 to $0.8 \mathrm{ng} / \mathrm{g}$ (LOQ) (see Table 2). However, method detection limits (MDLs, ng/g dw) and method quantification limits (MQLs, ng/g dw) are more appropriate for establishing environmental analysis detection thresholds. Calculation must take into account the stages of dilution or pre-concentration made during the sample preparation. In our case, a 5-fold dilution step is applied to the initial sample. Therefore, considering LODs values obtained in matrix, MDLs ranged from 0.5 to $1.5 \mathrm{ng} / \mathrm{g}$ (see Table 2). Thus, the developed analytical method allowed determination of the target analytes at concentration levels in the order of a few $\mathrm{ng} / \mathrm{g} \mathrm{dw}$ in mussels exposed in marine water.

\section{Specificity and selectivity}

The specificity of the method was assessed through the analysis of three blank mussel samples extracted by the optimized QuEChERS methodology. No other significant peaks ( $\mathrm{S} / \mathrm{N} \geq$ 3 ) were found at the specific retention times of target pharmaceuticals. On the other hand, in full scan mass spectrometry measurements, selectivity is obtained by creation of extracted ion chromatograms (EICs) of quasi-molecular ions of the compounds of interest. The use of HRMS enables data analysis using the EICs with a narrow mass-extraction window, which provides the required selectivity [27]. The retention times were together the accurate mass, the criteria established to carry out the identification of analytes in samples, taking into account a maximum mass deviation of $5 \mathrm{ppm}$ and considering chromatographic peak with $\mathrm{S} / \mathrm{N} \geq 3$. Furthermore, additional scans for the unambiguous identification of the target compounds present in the samples, via spectral acquisition with HCD fragmentation at $15 \mathrm{eV}$ were included in the analytical method. Therefore, two chromatograms are collected, one containing full-scan mass for non-fragmented ions and another for MS/MS data, which contains information about the fragmented ions obtained at fixed collision energy.

Analysis of real samples

The applicability of the proposed method was assessed for the analysis of marine mussel samples collected from different areas of the Mediterranean Sea located in southeaster France and local supermarkets in Montpellier (France). Analytes detection was based on extraction of the exact mass $(<5 \mathrm{ppm})$ of the precursor ion at the correct retention time $( \pm 30 \mathrm{~s})$ and the presence of almost $1 \mathrm{~s}$ product ion. All these identification criteria were compared with those obtained with matrix-matched calibration curves in the same batch, according to the recommendations established by Commission Decision 2002/657/EC37 [22]. Venlafaxine and its transformation products were detected in mussel samples during the monitoring program performed from January 2011 to 2013 . With regard to EU surface waters, their occurrence has been 
reported at concentrations ranging from some $\mathrm{ng} / \mathrm{L}$ to $1 \mu \mathrm{g} / \mathrm{L}$ [10-12]. In contrast, no studies in coastal waters or marine organisms have previously been reported for such compounds until now. Residues of the selected antidepressant drug (VEN) were occasionally detected in four marine mussel samples, but it was only found in one at concentration above its MQL $(2.5 \mathrm{ng} / \mathrm{g} \mathrm{dw})$. However, several transformation products were detected at higher levels. $N$-desmethylvenlafaxine (NDV) was the most frequently identified metabolite followed by $N$, Odidesmethylvenlafaxine (NODDV) at levels up to 3.0 and $3.5 \mathrm{ng} / \mathrm{g} \mathrm{dw}$, respectively. All the results obtained are summarized in Table 3.

Several studies have reported higher concentrations of ODV than VEN in treated waste water and surface water, with a mean ratio of approximately 5:1 [7]. The same ratio was observed by Nakamura et al. [28] in fish (Oryzias latipes) exposed to antidepressant fluoxetine. Such research showed that its metabolite (norfluoxetine) presented concentrations five times greater than fluoxetine levels. However, lack of bioaccumulation experiments that allow us to justify the hypothesis of the VEN metabolism in mussels, it is difficult to determine whether the metabolites were present in the mussels as a result of the metabolization of the organisms, or as a result of direct uptake from water. In any event, as it has previously been discussed by other scientific, the metabolite profile varied significantly among species. ODV is the major metabolite in humans, but not in mouse, rat, dog, or monkey [3]. Therefore, it is not appropriate to assume the same metabolic reactions in mussels and in human. In any case, our results are in agreement with other studies. Metcalfe et al. [9] observed residues of VEN and NDV at mean concentrations of 1.2 and $2.18 \mu \mathrm{g} / \mathrm{kg}$ wet weight in caged fish muscle collected downstream of a WWTP in Canada. In this study, ODV was also detected, but at levels below its limits of quantification $(0.5 \mu \mathrm{g} / \mathrm{kg} \mathrm{ww})$. A recent work (in 2013) reports the occurrence of 17 pharmaceuticals and personal care products (PPCPs) and three alkylphenols (APs) in benthic mussels (Geukensia demissa) collected from an urban estuary (San Francisco Bay, USA) [29]. In this study, similar concentrations as ours were found for another antidepressant (sertraline), up to $1.4 \mathrm{ng} / \mathrm{g}$ ww using $5.5 \mathrm{~g}$ of wet tissue.

No analyte was detected in the samples purchased in different local supermarkets in France ( $n=4)$, or in mussel samples taken from the production cultures or reference zone ( $\mathrm{n}=$ 4). Finally, only one metabolite (NNDDODV) was not detected in samples from our monitoring campaign. In any case, the recovery of the surrogate standards was above $75 \%$ for each analyzed sample. These standards allowed us to verify that the extraction method, performance, and analysis were satisfactory. An example of identification of a sub-product of VEN in a marine mussel sample is presented in Fig. 2. In full MS spectrum, the measured mass for NNDDV is shown at $\mathrm{m} / \mathrm{z}$ 250.17879 , which matches the theoretical mass 250.1801 with an error of $-3.6 \mathrm{ppm}$. The additional acquisition in full MS/ MS mode provided a more comprehensive identification of this compound as well as its structural characterization found for the characteristic fragment ion at $\mathrm{m} / \mathrm{z} 201.12748$ with a mass deviation of $-2.30 \mathrm{ppm}$. Good mass accuracies were obtained both in the MS and MS/MS scans ( $<5 \mathrm{ppm})$. Thus, a correct identification was ensured in line with the other evaluated parameter (retention time, Rt).

The results support the hypothesis of a moderate bioconcentration for VEN in aquatic organisms, despite its modest octanol-water partition coefficient $\mathrm{K}_{\mathrm{ow}} 3.28$ [7, 30]. Bioconcentration factors are often described as being associated with the lipophilicity of the molecule. However, in line with previous studies, the accumulation not always increased with a linear relation, suggesting other bioconcentration mechanisms such as biotransformation. Gómez et al. [16] explained these differences by possible clearance mechanisms/metabolization in marine mussels. Thus, although the initial results were positive, future experiments should be conducted on the bioaccumulation of VEN and its metabolites in marine mussels in order to assess their bioconcentration factors and therefore obtain data regarding its distribution and persistence in marine aquatic organisms. Also, this data will be useful in retrospective ecological risk assessments to support an understanding of environmental exposure as well as to predict toxic effects in marine organisms.

\section{Spatial-temporal variation}

In order to monitor the fluctuations in the occurrence of target compounds in study area, seasonal and monthly variations were also evaluated (see results Table 3). As can be seen, a greater number of analytes were identified in the sample collected at east points in the vicinity of a submarine outfall, during the first months of the year (January to April). This may be due to two processes: (1) differences in ocean currents or (2) a possible increase in the consumption of these types of drug to treat disorders related to depression during those months. Several factors associated with anxiety and stress can be caused by the post-holiday period or by winter weather. In fact, very few compounds were found in the months following the summer (September to December).

On the other hand, in relation to the localization variation, although Marseille exhibits a greater population than Montpellier ( 1.5 million people versus 0.25 , respectively), it is an interesting highlight that traces of some target compounds were not detected in Marseille during the monitoring camping carried out in September 2012. This could be due to greater efficiency of the treatment plant in Marseilles, or by the differences in emissaries settings (submarine outfall in Montpellier/superficial emissary in Marseille), which would lead to a different dispersion of pollutants. Similarly, during the same sampling period in Montpellier area, some metabolites of VEN were only identified in the sample collected from lagoon 
Table 3 Concentration of venlafaxine and its metabolites (ng/g dw) in 34 samples of marine mussel samples (M. galloprovincialis) collected during the time the monitoring program was carried out

\begin{tabular}{|c|c|c|c|c|c|c|c|c|}
\hline Sampling Point & & $\begin{array}{l}\text { Exposure period } \\
\text { (day/month) }\end{array}$ & $\begin{array}{l}\text { NNDDODV } \\
(\mathrm{ng} / \mathrm{g} \mathrm{dw})\end{array}$ & $\begin{array}{l}\text { NODDV } \\
(\mathrm{ng} / \mathrm{g} \mathrm{dw})\end{array}$ & $\begin{array}{l}\text { ODV } \\
(\mathrm{ng} / \mathrm{g} \mathrm{dw})\end{array}$ & $\begin{array}{l}\text { NNDDV } \\
(\mathrm{ng} / \mathrm{g} \mathrm{dw})\end{array}$ & $\begin{array}{l}\text { NDV } \\
(\mathrm{ng} / \mathrm{g} \mathrm{dw})\end{array}$ & $\begin{array}{l}\text { VEN } \\
(\mathrm{ng} / \mathrm{g} \mathrm{dw})\end{array}$ \\
\hline \multicolumn{9}{|l|}{ Montpellier } \\
\hline \multirow[t]{6}{*}{ Jan-2011 } & To & & / & l & / & l & / & l \\
\hline & IM & $25 / 01-22 / 03$ & l & l & l & l & $<\mathrm{MQL}$ & l \\
\hline & IM & $25 / 01-26 / 05$ & / & / & l & l & 1 & l \\
\hline & $\mathrm{N}$ & $25 / 01-22 / 03$ & l & 3.0 & l & l & 2.5 & l \\
\hline & $\mathrm{E}$ & $25 / 01-22 / 03$ & / & 1 & $<\mathrm{MDL}$ & l & 2.9 & $<\mathrm{MQL}$ \\
\hline & W & $25 / 01-22 / 03$ & I & 3.5 & 1 & I & 3.0 & 1 \\
\hline \multirow[t]{5}{*}{ Mars-2011 } & To & & l & 1 & l & I & / & l \\
\hline & IM & $22 / 03-24 / 05$ & I & l & l & I & l & l \\
\hline & $\mathrm{N}$ & $22 / 03-24 / 05$ & l & l & l & I & l & l \\
\hline & $\mathrm{E}$ & $22 / 03-24 / 05$ & l & / & 3.7 & l & $<\mathrm{MQL}$ & $<\mathrm{MQL}$ \\
\hline & $\mathrm{W}$ & $22 / 03-24 / 05$ & l & I & 1 & I & 1 & 1 \\
\hline \multirow[t]{5}{*}{ April-2012 } & To & & l & / & l & I & / & l \\
\hline & IM & $12 / 04-21 / 06$ & l & l & l & l & l & l \\
\hline & $\mathrm{N}$ & $12 / 04-21 / 06$ & l & 2.5 & l & I & I & I \\
\hline & $\mathrm{E}$ & $12 / 04-21 / 06$ & l & 1 & l & I & 2.5 & 2.7 \\
\hline & $\mathrm{W}$ & $12 / 04-21 / 06$ & l & l & l & l & 1 & 1 \\
\hline \multirow[t]{5}{*}{ Sept-2012 } & IM & 02/09-06/09 & l & l & l & 3.8 & $<\mathrm{MDL}$ & $<\mathrm{MQL}$ \\
\hline & Ref & 06/09-03/12 & l & I & l & 1 & 1 & 1 \\
\hline & $\mathrm{N}$ & 06/09-03/12 & l & l & l & l & l & l \\
\hline & $\mathrm{E}$ & 06/09-03/12 & / & l & l & I & / & $<\mathrm{MQL}$ \\
\hline & $\mathrm{W}$ & 06/09-loss & n.a & n.a & n.a & n.a & n.a & n.a \\
\hline \multirow[t]{3}{*}{ Dec-2012/13 } & Ref & 03/12-05/03 & / & 1 & / & / & l & l \\
\hline & $\mathrm{N}$ & $03 / 12-05 / 03$ & I & l & l & l & l & / \\
\hline & $\mathrm{E}$ & $03 / 12-05 / 03$ & / & l & l & I & l & l \\
\hline \multicolumn{9}{|l|}{ Marseille } \\
\hline \multirow[t]{7}{*}{ Sept-2012 } & To & & l & l & / & I & l & l \\
\hline & $\operatorname{Ref}_{\mathrm{s}}$ & 09/09-05/12 & l & l & / & l & l & l \\
\hline & $\operatorname{Ref}_{\mathrm{m}}$ & 09/09-05/12 & l & 1 & / & 1 & l & l \\
\hline & $\mathrm{N}_{\mathrm{s}}$ & $10 / 09-05 / 12$ & 1 & l & / & 1 & l & l \\
\hline & $\mathrm{N}_{\mathrm{m}}$ & $10 / 09-05 / 12$ & l & l & I & l & l & l \\
\hline & $\mathrm{E}_{\mathrm{s}}$ & $10 / 09-05 / 12$ & l & l & l & l & l & l \\
\hline & $\mathrm{E}_{\mathrm{m}}$ & $10 / 09-05 / 12$ & l & l & l & l & / & l \\
\hline \multicolumn{9}{|l|}{ Supermarket } \\
\hline June-2011 & $\# 1$ & $30 / 06 / 2011$ & l & l & l & l & / & l \\
\hline Sept-2011 & $\# 2$ & $15 / 09 / 11$ & l & l & l & l & l & l \\
\hline Nov-2012 & $\# 3$ & $10 / 11 / 12$ & l & l & l & l & l & l \\
\hline Jan-2013 & $\# 4$ & $19 / 01 / 12$ & l & l & l & I & l & l \\
\hline
\end{tabular}

To: before exposure; IM: lagoon point; N: north emissary point; E: east emissary point; W: west emissary point; Ref: reference zone or production cultures; $X_{\mathrm{s}}$ : samples placed on the surface of the water column; $X_{\mathrm{m}}$ : samples placed in the middle of the water column; n.a: data not available, sample loss; $<$ MQL/MDL: below to method quantification/detection limit (ng/g dw)

(IM: September 2012). This can be explained because this batch of mussels (September 2012), after its purchase, had to be immersed for several days in a lagoon of the area before its distribution to the different sampling points studied. In contrast, it is worth noting here that in the other samples taken from the lagoon points, we did not detect anything. That is because in all cases, except for the sampling carried out in September, the mussel batch was immersed in the lagoon for only a few hours until its distribution. However, the batch used in September, due to a problem with the boat, had to be 


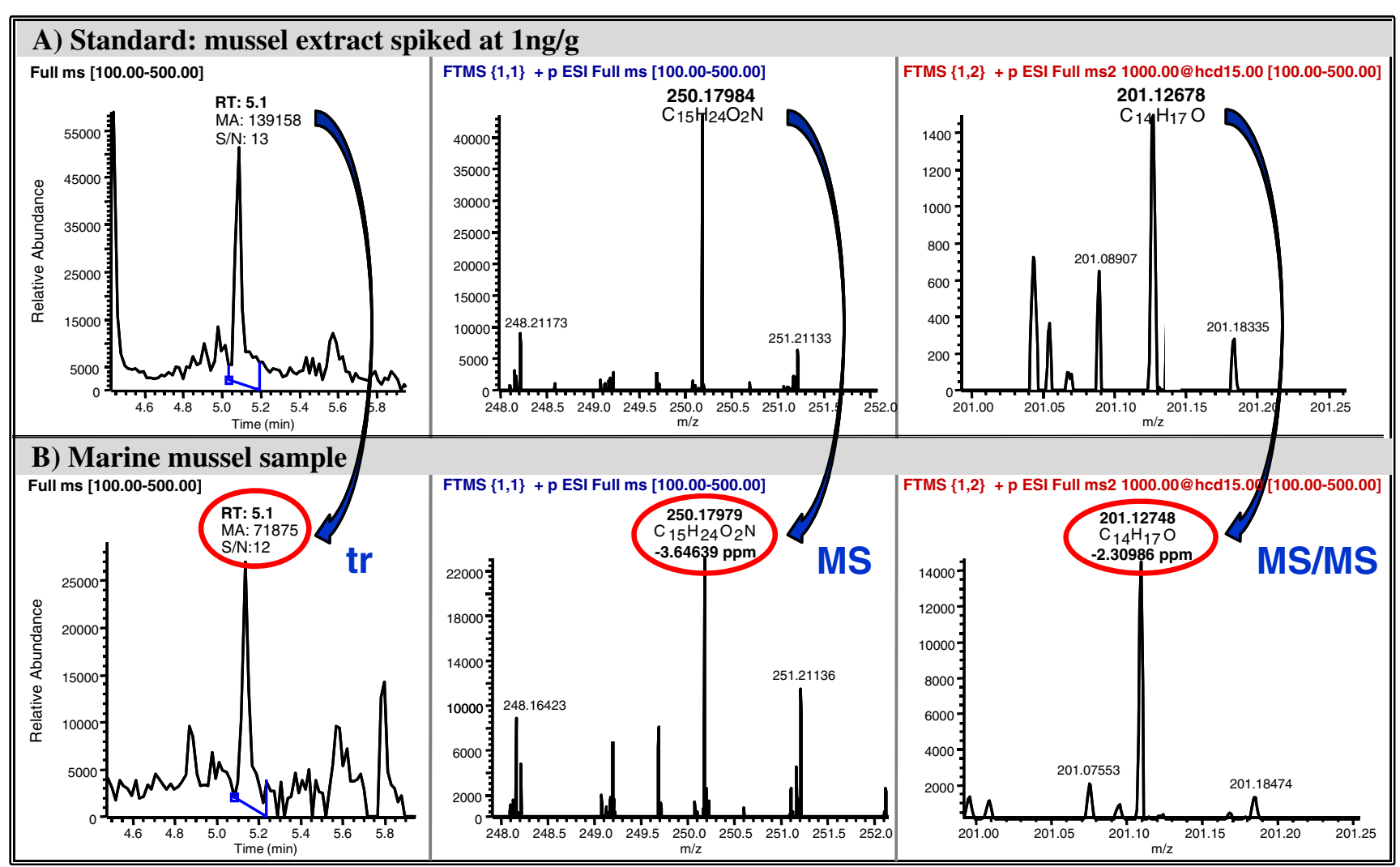

Fig. 2 Example of the identification of $N, N$-didesmethylvenlafaxine (NNDDV), a metabolite of antidepressant venlafaxine in a marine mussel sample, based on MS and MS/MS information

immersed in the lagoon for 5 days. Thus, the results support the hypothesis of a higher contamination of the waters of the lagoon compared with marine waters. The lagoon is connected to the Mediterranean Sea and is the largest in the region of Languedoc-Roussillon. They receive inputs from various human activities (i.e., urban activities, industries, port activities, and agriculture. Besides, the spa tourism is an important activity in that area, being the second thermal station in France and the first of the Mediterranean. Finally, note that no differences were observed when a same point was sampled at different levels in the water column (samples placed in the surface versus middle of the water column).

\section{Conclusions}

This paper reports for the first time results on the presence of a highly prescribed antidepressant (venlafaxine) and some of its main transformation products in marine organisms. As part of this study, an analytical approach including QuEChERS extraction and analysis by LCOrbitrap-MS system was developed. The method was validated according to the most demanding requirements regarding mass spectrometric confirmation and quality measurement criteria currently set by EU regulations, in order to ensure satisfactory positive results. The main advantages of the extraction protocol proposed in this study (QuEChERS) are its economy, simplicity, and speed. Moreover, this approach allowed obtaining high recoveries even to polar compounds, which is a common characteristic of the metabolites. Venlafaxine and some of its sub-products were found in marine mussels at trace levels $(\mathrm{ng} / \mathrm{g} \mathrm{dw})$ during the monitoring program carried out. The results show that the presence of target compounds varied depending on localization or the season.

On the other hand, these organisms have proven to be a useful tool for monitoring of organic compounds from marine waters. The work provides additional broadinterest data regarding to knowledge of transformation product concentration levels in aquatic organisms, which were not previously described. Finally, monitoring data indicated that the general population may be exposed to VEN and its metabolites, providing another possible exposure route and raising questions about human health consequences. To date, information on pharmaceuticals and personal care products (PPCPs) in aquatic organisms indicate that an additional understanding about their accumulation is necessary in order to characterize ecological and human health risks of such substances in the environment. Although the initial results were positive, future 
experiments should be conducted on the bioaccumulation of VEN and its metabolites in marine mussels.

Acknowledgments The authors are very grateful for the financial support given by the Sanofi and the French Agence Nationale de la Recherche (Project PEPSEA). This work was conducted within the Chair Emerging Pollutants (Veolia-Hydrosciences). The authors also gratefully acknowledge IFREMER for assistance with mussel collection and oceanographic ship EUROPE. M.J. Martínez Bueno thanks UM1 (University of Montpellier) for the postdoctorate grant.

\section{References}

1. Focazio MJ, Kolpin DW, Barnes KK, Furlong ET, Meyer MT, Zaugg SD, Barber LB, Thurman ME (2008) A national reconnaissance for pharmaceuticals and other organic wastewater contaminants in the United States - II. Untreated drinking water sources. Sci Total Environ 402:201-216

2. Recommendation of the European parliament and of the council of 30 May 2002 concerning the implementation of Integrated Coastal Zone Management in Europe (2002/413/EC). Official Journal of the European Communities L 148 of 6.6.2002

3. Howell SR, Husbands GEM, Scatina GA, Sisenwine SF (1993) Metabolic disposition of super (14)C-venlafaxine in mouse, rat, dog, rhesus monkey, and man. Xenobiotica 23:349-359

4. Thomas MA, Klaper RD (2012) Psychoactive pharmaceuticals induce fish gene expression profiles associated with human idiopathic autism. PLoS ONE. doi:10.1371/journal.pone.0032917

5. Martínez Bueno MJ, Gómez MJ, Herrera S, Hernando MD, Agüera A, Fernández-Alba AR (2012) Occurrence and persistence of organic emerging contaminants and priority pollutants in five sewage treatment plants of Spain: 2-years pilot survey monitoring. Environ Pollut 164:267-273

6. Lajeunesse A, Gagnon C, Sauve S (2008) Determination of basic antidepressants and their $\mathrm{N}$-desmethyl metabolites in raw sewage and wastewater using solid-phase extraction and liquid chromatographytandem mass spectrometry. Anal Chem 80:5325-5333

7. Rúa-Gómez PC, Püttmann W (2012) Occurrence and removal of lidocaine, tramadol, venlafaxine, and their metabolites in German wastewater treatment plants. Environ Sci Pollut Res 19:689-699

8. Schultz MM, Furlong ET, Kolpin DW, Werner SL, Schoenfuss HL, Barber LB, Blazer VS, Norris DO, Vajda AM (2010) Antidepressant pharmaceuticals in two US effluent-impacted streams: occurrence and fate in water and sediment, and selective uptake in fish neural tissue. Environ Sci Technol 44:918-1925

9. Metcalfe CD, Chu S, Judt C, Li H, Oakes KD, Servos MR, Andrews DM (2010) Antidepressants and their metabolites in municipal wastewater, and downstream exposure in an urban watershed. Environ Toxicol Chem 29:79-89

10. de Jongh CM, Kooij PJF, de Voogt P, ter Laak TL (2012) Screening and human health risk assessment of pharmaceuticals and their transformation products in Dutch surface waters and drinking water. Sci Total Environ 428:70-77

11. Valcárcel Y, González Alonso S, Rodríguez-Gil JL, Gil A, Catalá M (2011) Detection of pharmaceutically active compounds in the rivers and tap water of the Madrid region (Spain) and potential ecotoxicological risk. Chemosphere 84:1336-1348

12. Rúa-Gómez PC, Püttmann W (2012) Impact of wastewater treatment plant discharge of lidocaine, tramadol, venlafaxine, and their metabolites on the quality of surface waters and groundwater. J Environ Monit 14:1391-1399
13. Martínez Bueno MJ, Hernando MD, Agüera A, Fernández-Alba AR (2009) Application of passive sampling devices for screening of micropollutants in marine aquaculture using LCMSMS. Talanta 77:1518-1527

14. Zabiegala B, Kot-Wasik A, Urbanowicz M, Namiesnik J (2010) Passive sampling as a tool for obtaining reliable analytical information in environmental quality monitoring. Anal Bioanal Chem 396:273-279

15. Munaron D, Tapie N, Budzinski H, Andral B, Gonzalez JL (2012) Pharmaceuticals, alkylphenols and pesticides in Mediterranean coastal waters: results from a pilot survey using passive samplers. Estuar Coast Shelf Sci 114:82-92

16. Gómez E, Bachelot M, Boillot C, Munaron D, Chiron S, Casellas C, Fenet H (2012) Bioconcentration of two pharmaceuticals (benzodiazepines) and two personal care products (UV filters) in marine mussels (Mytilus galloprovincialis) under controlled laboratory conditions. Environ Sci Pollut Res 19:2561-2569

17. Baumard P, Budzinski H, Garrigues P (1998) Polycyclic aromatic hydrocarbons in sediments and mussels of the western Mediterranean Sea. Environ Toxicol Chem 17(5):765-776

18. Available at: http://pubchem.ncbi.nlm.nih.gov/summary/summary. cgi? $\mathrm{cid}=5656 \&$ loc $=\mathrm{ec}$ res. Accessed July 2013

19. Togundea OP, Oakesb KD, Servosb MR, Pawliszyna J (2012) Optimization of solid phase microextraction for non-lethal in vivo determination of selected pharmaceuticals in fish muscle using liquid chromatography-mass spectrometry. J Chromatogr A 1261:99-106

20. Ramirez AJ, Brain RA, Usenko S, Mottaleb MA, O'Donnell JG, Stahl LL, Wathen JB, Snyder BD, Pitt JL, Perez-Hurtado P, Dobbins LL, Brooks BW, Chambliss CK (2009) Occurrence of pharmaceuticals and personal care products (PPCPs) in fish: results of a national pilot study in the US. Environ Toxicol Chem 28:2587-2597

21. Anastassiades M, Lehotay SJ, Stajnbaher D, Schenck FJ (2003) Fast and easy multi-residue method employing acetonitrile extraction/partitioning and "dispersive solid-phase extraction" for the determination of pesticide residues in produce. J AOAC Int 86:412-431

22. Commission Decision 2002/657/EC (2002) Off J Eur Communities L221:8

23. SANCO (2010) Method validation and quality control procedures for pesticide residues analysis in food and feed. Document no. SANCO/ $10684 / 2009$

24. Martínez Bueno MJ, Boillot C, Fenet H, Chiron S, Casellas C, Gómez E (2013) Fast and easy extraction combined with high resolution-mass spectrometry for residue analysis of two anticonvulsants and their transformation products in marine mussels. J Chromatogr A 1305:27-34

25. ISO/IEC/EN 17025 general requirements for the competence of calibration and testing laboratories

26. Fernandez-Alba AR (2004) Chromatographic-mass spectrometric food analysis for trace determination of pesticide residues. In: Fernandez-Alba AR (ed) Comprehensive analytical chemistry, vol. XLIII. Amsterdam, Elsevier

27. Kellmann M, Muenster H, Zomer P, Mol H (2009) Full scan MS in comprehensive qualitative and quantitative residue analysis in food and feed matrices: how much resolving power is required? J Am Soc Mass Spectrom 20:1464-1476

28. Nakamura Y, Yamamoto H, Sekizawa J, Kondo T, Hirai N, Tatarazako N (2008) The effects of pH on fluoxetine in Japanese medaka (Oryzias latipes): acute toxicity in fish larvae and bioaccumulation in juvenile fish. Chemosphere 70:865-873

29. Klosterhaus SL, Grace R, Hamilton MC, Yee D (2013) Method validation and reconnaissance of pharmaceuticals, personal care products, and alkylphenols in surface waters, sediments, and mussels in an urban estuary. Environ Int 54:92-99

30. Environmental Science Center of Syracuse Research Corporation (SRC), EPI Suite ${ }^{\mathrm{TM}}$ Estimation Software, US Environmental Protection Agency (EPA) (2001) Available at: http://www.epa.gov/ oppt/exposure/docs/episuitedl.htm. Accessed 